\title{
Ablative techniques in hepatocellular carcinoma treatment
}

\author{
Ehsun Naeem, Shahab Abid \\ Section of Gastroenterology, Department of Medicine, Aga Khan University, Karachi 74800, Pakistan.
}

Correspondence to: Prof. Shahab Abid, Section of Gastroenterology, Department of Medicine, Aga Khan University, Stadium Road P.O Box 3500, Karachi 74800, Pakistan. E-mail: shahab.abid@aku.edu

How to cite this article: Naeem E, Abid S. Ablative techniques in hepatocellular carcinoma treatment. Hepatoma Res 2018;4:18. http://dx.doi.org/10.20517/2394-5079.2018.22

Received: 17 Mar 2018 First Decision: 22 Mar 2018 Revised: 8 May 2018 Accepted: 17 May 2018 Published: 13 Jun 2018

Science Editor: Guang-Wen Cao Copy Editor: Jun-Yao Li Production Editor: Cai-Hong Wang

\begin{abstract}
Hepatocellular carcinoma has been known to arise commonly in the setting of chronic liver disease. Due to its association with cirrhosis, patients with hepatocellular carcinoma often present with markedly diminished hepatic functional reserve, making them poor surgical candidates. For such patients, image-guided percutaneous ablative modalities have provided a viable alternate curative therapy. Although treatment allocation is a decision based on a number of factors, patients eligible for percutaneous ablation generally include those with early stage disease, hepatocellular carcinoma with disease limited to the liver and no extra-hepatic metastases. While percutaneous ethanol injection is the seminal technique, newer developments have led to it being replaced by percutaneous radiofrequency ablation as the most commonly employed procedure, due to a better efficacy as well as safety profile. Other ablative modalities including microwave ablation, laser ablation and cryotherapy are not as widely available. Furthermore, data comparing their effectiveness with well-established procedures like radiofrequency ablation is limited.
\end{abstract}

Keywords: Barcelona Clinic liver Cancer staging, chronic liver disease, hepatocellular carcinoma, Milan Criteria, percutaneous ethanol injection, radiofrequency ablation, surgical resection

\section{INTRODUCTION}

The past two decades have seen percutaneous ablation emerge as an exciting new therapeutic approach for the treatment of hepatic malignancies worldwide. While surgery is still regarded as the mainstay of therapy for hepatocellular carcinoma (HCC), high tumor burden and reduced hepatic functional reserve, as often encountered in such patients, precludes surgical resection in a significant proportion of patients ${ }^{[1]}$. For such

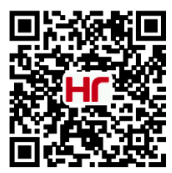


patients, image guided local ablation has provided a viable curative option that has significantly prolonged survival and improved cure rates ${ }^{[2]}$.

As the fourth leading cause of cancer related deaths in the world ${ }^{[3]}$, hepatocellular carcinoma remains one of the most feared complications of liver cirrhosis to date. The tremendously high case-fatality rate of this malignancy is often attributed to the relatively advanced stage of disease at the time of diagnosis in most cases $^{[3,4]}$. Although adoption of intensive surveillance programs for patients with underlying chronic liver disease have allowed for earlier detection of $\mathrm{HCC}^{[5]}$, prognosis remains poor for most patients, as evidenced by the short median survival following diagnosis, ranging from 6-20 months ${ }^{[6]}$. Nevertheless, most guidelines recommend screening at-risk individuals, such as those with chronic liver disease, with a non-invasive and cost-effective radiological investigation like ultrasound every 6 months.

HCC arises most often in the setting of cirrhosis, with an incidence of HCC development being as high as 1\%-8\% per year in chronic liver disease patients. Furthermore, the disease prevalence has been found to reflect the geographical distribution of the risk factors for cirrhosis ${ }^{[7]}$. Areas with a high prevalence rate include Eastern Asia and Sub-Saharan Africa due to the presence of chronic HBV infection, which is considered to be the dominant risk factor for chronic liver disease $\mathrm{e}^{[8,9]}$.

Optimal therapeutic approach is individualized to each patient, and should ideally be determined by a multi-disciplinary team comprising of hepatologists, surgeons, oncologists, radiologists, interventional radiologists and pathologists due to the complexity of the disease. Factors that need to be considered when determining treatment approach include liver function, size and number of nodules, tumour extension, age and co-morbid conditions of the patient. Nature of the underlying chronic liver disease may also play a part in this decision, particularly in cases where the oncogenic agent is expected to persist following treatment, reducing the viability of invasive procedures like surgical resection.

Guidelines such as The European Association for the study of Liver and The American Association for the Study of Liver Diseases recommend algorithms based on the Barcelona Clinic Liver Cancer staging system for the purpose of staging and treatment allocation. Although it has a number of limitations, the BCLC staging system has been validated in different settings and is commonly employed in many countries ${ }^{[10]}$. The algorithm stratifies patients into five categories, based on the disease stage. In general, potentially curative treatments such as tumor resection, liver transplantation and percutaneous ablation are reserved for patients with early stage disease, classified as BCLC stage 0 and BCLC stage A, while patients in BCLC stage B, C and $\mathrm{D}$ presenting with advanced disease are offered palliative treatment options like chemoembolization and Sorafenib or supportive care [Figure 1].

Since their introduction, The Milan Criteria have become the standard guidelines for hepatic transplantation ${ }^{[11]}$. These criteria restrict liver transplant to patients with either a single tumor less than $5 \mathrm{~cm}$ in diameter or less than three foci of tumor each with a diameter of no more than $3 \mathrm{~cm}$, absence of angio-invasion and extra hepatic involvement. Using these criteria, excellent 5 -year survival rates of $70 \%$ or greater and a $15 \%$ recurrence rate have been demonstrated by multiple studies, indicating their importance in predicting prognosis in HCC patients undergoing liver transplant. The Milan Criteria has also been found to produce excellent results when used for treatment allocation of patients with early stage disease, who may be candidates for other curative procedures like surgical resection or loco-regional ablative treatments

\section{PERCUTANEOUS LOCAL ABLATION}

Since their advent in the 1990s, percutaneous local ablative techniques have been continuously evolving owing to rigorous research and clinical testing in this area ${ }^{[12]}$. While percutaneous ethanol injection was regarded as the primary ablative therapy up until the turn of the century, recent years have seen it largely 


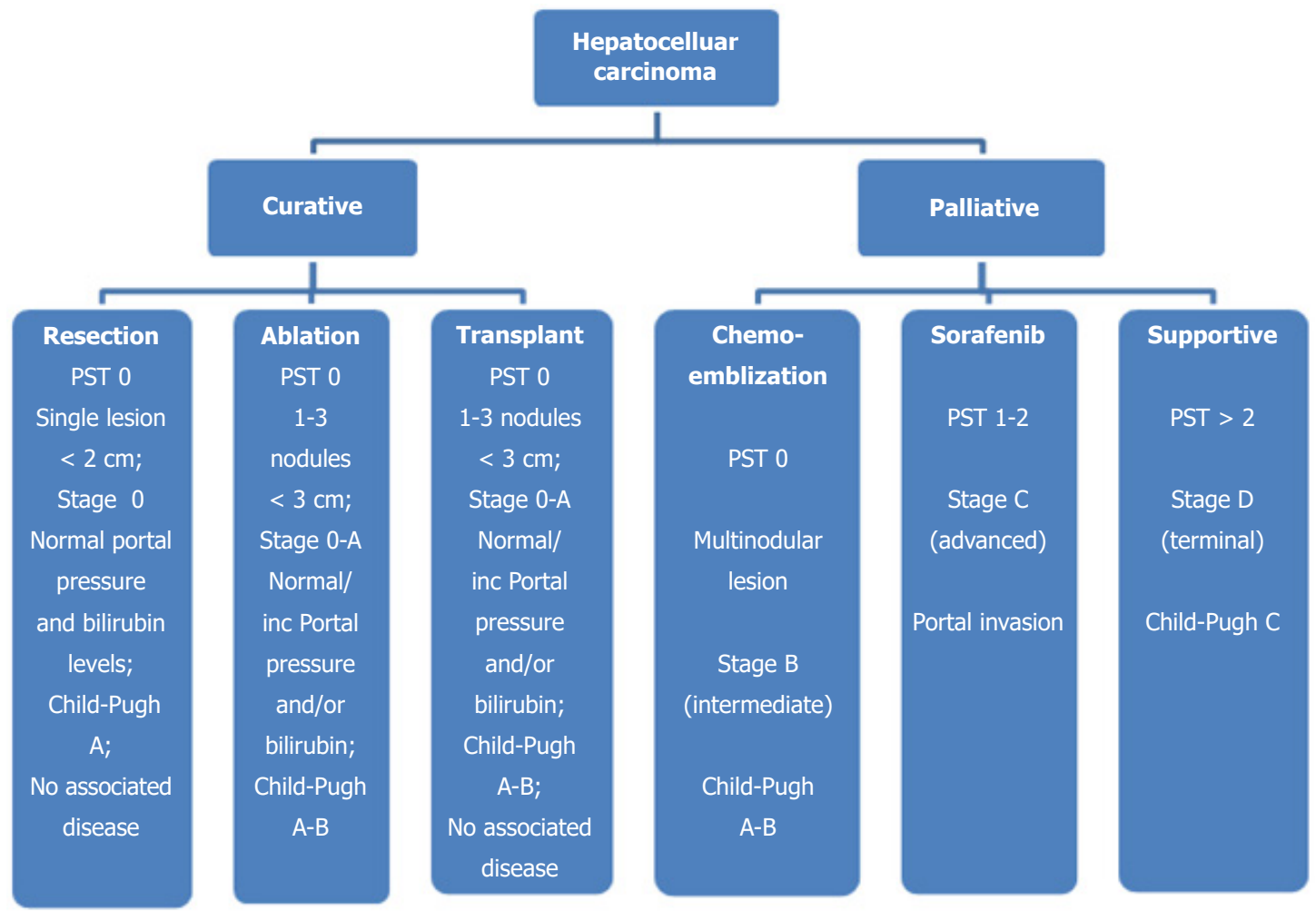

Figure 1. Treatment algorithm based on disease and patient characteristics, adapted from the BCLC staging system

being replaced by newer modalities like Radiofrequency ablation. Although encouraging results have been reported for both in terms of treatment response and long-term survival, differences exist in terms of applicability and adverse effects of each, and the decision to use one over the other is often individualized to each patient and requires careful patient evaluation and triage.

\section{PERCUTANEOUS ETHANOL INJECTION}

Percutaneous ethanol injection (PEI), performed under local anaesthesia with ultrasound guidance, involves injecting ethanol intra-lesionally using non-cutting needles over multiple sessions in the outpatient setting. By promoting cellular dehydration and occlusion of smaller tumor vessels, ethanol induces coagulative necrosis and a fibrous reaction leading to complete necrosis of most lesions. PEI is a well-established therapy, particularly for the treatment of nodular HCC, owing to the ability of ethanol to diffuse through the soft malignant tissue and the firm consistency of the surrounding cirrhotic liver parenchyma ${ }^{[13]}$.

In general, tumour response following PEI is determined by the size of the lesion as well the degree of hepatic dysfunction. Tumours smaller than $2 \mathrm{~cm}$ show the best response in terms of disease eradication with $90 \%-100 \%$ of lesions showing complete response, while larger lesions have shown a high rate of local recurrence when treated with $\mathrm{PEI}^{[14-16]}$. This is postulated to be due to septae within larger lesions, presenting barriers to the diffusion of ethanol, leading to an incomplete response. With recent technological advances however, including the introduction of a multipronged needle with retractable prongs, even larger tumors up to $4 \mathrm{~cm}$ in size have demonstrated complete response rates as high as $80 \%-90 \%{ }^{[17]}$.

With 5-year survival rates as high as $47 \%-53 \%$ in patients with early stage disease, PEI has shown encouraging results ${ }^{[18,19]}$. It is however, associated with a high local recurrence rate of $43 \%$, particularly for lesions larger than $3 \mathrm{~cm}$ in diameter, which undermines its curative capacity when compared with newer ablative modalities like radiofrequency ablation (RFA) $)^{[20]}$. 
PEI may be considered as an alternate curative approach for patients with limited hepatic malignancies who are poor surgical candidates. High local recurrence rates preclude PEI in patients with tumours larger than $5 \mathrm{~cm}$, or with a volume in excess of $30 \%$ of the total liver volume. Other contraindications include extra-hepatic disease, involvement of the dome of the liver, portal vein thrombosis and ChildPugh class $\mathrm{C}$ cirrhosis.

Although rare, serious adverse effects associated with PEI include intra-peritoneal haemorrhage, liver failure, bile duct necrosis or biliary fistula, portal vein thrombosis, hepatic infarction, hypotension and renal failure ${ }^{[21]}$. The incidence of such major complications has been found to be as low as $2.2 \%$ according to some studies. Other minor side effects experienced more commonly include localized pain and peritoneal irritation secondary to ethanol leakage ${ }^{[22]}$.

\section{THERMAL ABLATION}

Thermal ablative therapies for HCC include hyper-thermic treatments like radiofrequency ablation, microwave ablation, and laser ablation as well as cryotherapy. Hyper thermic modalities typically achieve destruction of the tumor by exposing the tissues to cytotoxic temperatures. While hyper-thermic techniques are mostly administered using a percutaneous approach, open or laparoscopic approach is often employed for cryotherapy ${ }^{[23]}$. Compared to RFA, Laser and microwave ablation have not been as well studied and are not widely available.

\section{RFA}

By generating an alternating electric field within the tissues using a needle electrode, radiofrequency ablation relies on ionic vibrations to generate large amounts of frictional heat, inducing temperatures in excess of $60 \mathrm{C}$, leading to irreversible cellular damage ${ }^{[24]}$. By producing a safety ring within the peri-tumoral tissue, RFA is better able to achieve complete eradication of the primary lesion, as well as micro-satellites located within its proximity. Due to the larger ablation area of up to $3 \mathrm{~cm}$ with each application, RFA is also able to achieve complete eradication of the disease, requiring fewer number of electrode insertions, when compared with PEI.

Using RFA, treatment response has been found to correlate best with the size of the lesion; a complete response rate between $80 \%-90 \%$ in tumors up to $3 \mathrm{~cm}$ in diameter ${ }^{[24-27]}$, and $50 \%-70 \%$ in lesions between 3 and $5 \mathrm{~cm}$ in diameter ${ }^{[25,28-31]}$. Five-year survival rates following RFA were reported as $48 \%-71 \%$ by some studies $^{[32-34]}$. As with local tumor control, survival following RFA was also found to correlate best with the size of the lesions. For instance, three-year survival rates for lesions $>5 \mathrm{~cm}, 2.1$ to $5 \mathrm{~cm}$, and $\leq 2 \mathrm{~cm}$ have been reported as $59 \%, 74 \%$, and $91 \%$, respectively by a study comprising 302 patient $^{[35]}$.

When compared with PEI, significant differences have been observed particularly in terms of local control of the disease, as evidenced by local recurrence rates of only $2 \%-18 \%$ following RFA, as compared to $11 \%-45 \%$ in case of $\mathrm{PEI}^{[36-40]}$.

Like PEI, radiofrequency ablation is indicated in patients with early stage liver-only disease, who are candidates for curative therapy but do not meet the resectability criteria. It has also proven efficacious in the treatment of recurrent HCC lesions following partial hepatectomy ${ }^{[35,41]}$. It should however, be avoided in case of lesions located in the dome or the inferior edge of the liver due to the risk of diaphragmatic injury ${ }^{[42]}$. It is also advisable to avoid RFA in case of sub-capsular tumors located within $1 \mathrm{~cm}$ of the hepatic capsule, due to the risk of needle-track seeding, which was observed in 4 out of 32 patients in a series ${ }^{[43]}$ [Table 1]. 
Table 1. Contraindications to radiofrequency ablation. Adapted from reference ${ }^{[47]}$

\begin{tabular}{ll}
\hline Absolute & \multicolumn{1}{c}{ Relative } \\
\hline Decompensated liver disease (Child-Pugh C) & Lesions larger than $5 \mathrm{~cm}$ in diameter \\
Proximity to major hepatic ducts & $>3$ lesions \\
Extrahepatic disease & Severe coagulopathy \\
Altered mentation & Sub-capsular tumors \\
Active infection & Tumors within the dome of liver \\
\hline
\end{tabular}

With RFA, severe complications have been thought to occur at a rate of $2.2 \%-11 \%$, with procedural mortality rates of $0.1 \%-0.8 \%$. These include fatal, such as liver failure, colon perforation, and Portal Vein Thrombosis as well as non-fatal complications like liver abscesses, pleural effusion, skin burns, hypoxemia, pneumothorax, sub-capsular hematoma and hemo-peritoneum ${ }^{[30,44-46]}$. RFA, when employed for the ablation for sub capsular tumors located within $1 \mathrm{~cm}$ of the hepatic capsule, can also potentially lead to needle-track seeding, as has been observed in several studies.

\section{LASER ABLATION}

Percutaneous laser ablation employs laser fibers inserted directly into the tissues to deliver light energy capable of inducing coagulative necrosis within the malignant tissue. While the volume of necrosis that can be achieved with a single bare laser fiber is $2 \mathrm{~cm}$, a greater area of ablation can be achieved with the use of multiple fibers ${ }^{[18]}$.

The safety and efficacy of this technique are not as well-documented, and the availability of data comparing its effectiveness with other ablative modalities is limited. A complete response rate of $78 \%$ was observed following laser ablation in a study of 432 patients, while the local recurrence rate was found to be $20 \%$, with 3 - and 5-year survival rates as high as $61 \%$ and $34 \%$ respectively ${ }^{[48-50]}$. The safety of laser ablation has also been found to be comparable with other percutaneous modalities like RFA with major and minor complication rates of $1.5 \%$ and $6.2 \%$ respectively, and a mortality rate of $0.8 \%$ as reported by an Italian study ${ }^{[51]}$.

While these results may be encouraging, they do not provide evidence of greater efficacy or a better safety profile over alternate technology that is available at a much cheaper cost and hence, much more readily than percutaneous laser ablation ${ }^{[52]}$. These factors have restricted the use of laser ablation mostly to European countries.

\section{MICROWAVE ABLATION}

Most commonly used in China and Japan ${ }^{[53]}$, microwave ablation generates microwaves using implanted electrodes to induce molecular rotation, generating heat which is even being distributed evenly. By doing so, it creates an ablation area in the shape of the needle.

Like laser ablation, data for microwave ablation is also limited, but studies have indicated complete response rates between $89 \%$ and $95 \%$, while three and five-year survival rates have been reported as $73 \%$ and $57 \%$ respectively ${ }^{[25,54-58]}$. As seen in case of RFA, survival following microwave ablation was also affected by tumor size, number of nodules and Child-Pugh class.

When compared with RFA, although no significant differences in efficacy were observed, local recurrence and complication rates were found to be lower in case of RFA. Nevertheless, an important advantage favouring microwave ablation (MWA) over RFA is that its effectiveness is not limited by the proximity of the tumor to large vessels. Unlike RFA, MWA can also be used to perform multiple ablations simultaneously, in case of tumors with multiple foci, however this technique is not as widely available. 
Table 2. Comparison of overall 3- and 5-year survival rates following resection and radiofrequency ablation. Adapted from reference ${ }^{[60]}$

\begin{tabular}{lll}
\hline & Resection & Radiofrequency ablation \\
\hline Number of patients & 115 & 115 \\
3-year survival rate & $92.2 \%$ & $69.6 \%$ \\
5-year survival rate & $75.7 \%$ & $54.8 \%$ \\
\hline
\end{tabular}

\section{RFA VS. SURGICAL RESECTION}

Underlying chronic liver disease presents a significant challenge in the treatment of hepatocellular carcinoma. Hepatic failure often complicates surgical resection in cases where hepatic functional reserve is significantly depleted. The decision to avoid surgery and opt for alternate loco-regional ablative procedures in such cases thus seems rather prudent.

Where hepatic function is relatively preserved and lesions are amenable to resection, surgery is still regarded as the mainstay of therapy, although a case can be made to opt for Radiofrequency ablation here in light of the unavoidable risks of the procedure and the hospitalization. Even when performed by highly experienced surgeons, operative mortality rates ranging from $1.6 \%-10 \%$ have been observed in various studies ${ }^{[59]}$. Whereas percutaneous radiofrequency ablation is much less invasive, is associated with a lower rate of complications and mortality, and usually involves short hospital stays if needed at all. Unlike resection, it can also be used in cases where HCC arises in the setting of cirrhosis secondary to oncogenic stimuli expected to persist following treatment, such as metabolic conditions like hemochromatosis. Furthermore, RFA as well as PEI may be used as bridging therapies for patients with HCC scheduled to undergo liver transplant.

Unfortunately, studies directed at comparing the efficacy of RFA relative to surgical resection have failed to provide sufficient evidence to support its use in cases where patients may be candidates for both. In fact, some studies have even reported better outcomes, in terms of 3- and 5-year survival rates following surgical resection, as compared to RFA. The results of one such study performed on a cohort of 225 participants fulfilling the Milan criteria have been presented in Table 2 and show significantly higher survival rates for patients following resection ${ }^{[60]}$.

With careful patient selection and good operative technique, surgical resection has been shown to achieve 5-year and long-term survival rates of $78 \%$ and $40 \%$ respectively. Such optimal criteria for patient selection include patients with solitary lesions less than $5 \mathrm{~cm}$ in diameter, absence of angio-invasion or hepatic metastases, and adequate surgical margins of at least $1 \mathrm{~cm}$. Current guidelines such as AASLD also recommend hepatic resection over RFA for patients with resectable T1 or T2 HCC and Child-Pugh A cirrhosis.

\section{RFA VS. PEI}

While PEI has shown to be almost as equally effective as RFA for small tumours, and costs much less since it requires a minimal amount of equipment, its use has largely been restricted to situations where RFA might not be available or for lesions located near the gall bladder, hepatic hilum or major vessels, precluding thermal ablation ${ }^{[25]}$. Factors responsible for this may include peri-procedural pain and the need for multiple settings, both of which contribute to non-compliance, as well as higher local recurrence rates in comparison with RFA as observed by various randomized trials and meta-analyses ${ }^{[6]]}$.

While both RFA and PEI have proven their feasibility and applicability in cases where surgical resection is not a viable option, some studies do provide evidence of greater efficacy with the use of RFA, as evidenced by greater 3-year survival rates as well as the lower rate of local recurrence following its use, as summarized in Table $3^{[2]}$. 
Table 3. Differences in outcome following RFA and PEI, as reported by an Italian study comprising of 271 patients with a single lesions up to $3 \mathrm{~cm}$ in size. Adapted from reference ${ }^{[62]}$

\begin{tabular}{lll}
\hline & RFA & PEI \\
\hline Number of patients & 128 & 143 \\
3-year survival & 83 & 78 \\
5-year survival & 70 & 68 \\
Average number of sessions & 5 & 8 \\
Rate of major complications & $0.9 \%$ & $1.9 \%$ \\
Recurrence rate at 3 years & 7.8 & 9.4 \\
\hline
\end{tabular}

PEl: percutaneous ethanol injection; RFA: radiofrequency ablation

\section{CONCLUSION}

While surgical resection is still considered the standard of care for patients with early stage Hepatocellular carcinoma, percutaneous ablation has emerged as a viable alternative for the management of patients who are poor surgical candidates. Among percutaneous therapies, radiofrequency ablation has now replaced percutaneous ethanol injection as the treatment of choice for patients with BCLC 0-A tumors, not amenable to surgical resection, while ethanol injection is still recommended in cases where RFA is not technically feasible due to the inaccessible location of the lesions.

Radiofrequency ablation has shown the best results when used for smaller tumors, particularly those smaller than $3 \mathrm{~cm}$. While the percutaneous approach is employed most frequently, RFA can be administered via the laparoscopic or open approach as well, preferred in case of lesions located near the inferior edge of the liver, in close proximity to adjacent organs. Other emerging loco-regional procedures like microwave ablation, percutaneous laser ablation and cryotherapy are not as widely available and have not been studied as well.

\section{DECLARATIONS}

\section{Authors' contributions}

Developed the first draft: Naeem E

Modified and layout the concepts of tables and figure: Abid S

Reviewed the subsequent versions and final draft: Naeem E, Abid S

\section{Availability of data and materials}

Not applicable.

\section{Financial support and sponsorship}

None.

\section{Conflicts of interest}

Both authors declared that there are no conflicts of interest.

\section{Ethical approval and consent to participate}

Not applicable.

\section{Consent for publication}

Not applicable.

\section{Copyright}

(c) The Author(s) 2018. 


\section{REFERENCES}

1. Llovet JM, Burroughs A, Bruix J. Hepatocellular carcinoma. Lancet 2003;362:1907-17.

2. Bruix J, Sherman M, Llovet JM, Beaugrand M, Lencioni R, Burroughs AK, Christensen E, Pagliaro L, Colombo M, Rodés J; EASL Panel of Experts on HCC. Clinical management of hepatocellular carcinoma. Conclusions of the Barcelona-2000 EASL conference. European Association for the Study of the Liver. J Hepatol 2001;35:421-30.

3. Gobal burden of Disease Liver Cancer Collaboration, Akinyemiju T, Abera S, Ahmed M, Alam N, Alemayohu MA, Allen C, AlRaddadi R, Alvis-Guzman N, Amoako Y, Artaman A, Ayele TA, Barac A, Bensenor I, Berhane A, Bhutta Z, Castillo-Rivas J, Chitheer A, Choi JY, Cowie B, Dandona L, Dandona R, Dey S, Dicker D, Phuc H, Ekwueme DU, Zaki MS, Fischer F, Fürst T, Hancock J, Hay SI, Hotez P, Jee SH, Kasaeian A, Khader Y, Khang YH, Kumar A, Kutz M, Larson H, Lopez A, Lunevicius R, Malekzadeh R, McAlinden C, Meier T, Mendoza W, Mokdad A, Moradi-Lakeh M, Nagel G, Nguyen Q, Nguyen G, Ogbo F, Patton G, Pereira DM, Pourmalek F, Qorbani M, Radfar A, Roshandel G, Salomon JA, Sanabria J, Sartorius B, Satpathy M, Sawhney M, Sepanlou S, Shackelford K, Shore H, Sun J, Mengistu DT, Topór-Mądry R, Tran B, Ukwaja KN, Vlassov V, Vollset SE, Vos T, Wakayo T, Weiderpass E, Werdecker A, Yonemoto N, Younis M, Yu C, Zaidi Z, Zhu L, Murray CJL, Naghavi M, Fitzmaurice C. The burden of primary liver cancer and underlying etiologies from 1990 to 2015 at the global, regional and national level: results from the global burden of disease study 2015. JAMA Oncol 2017;3:1683.

4. Jemal A, Bray F, Center MM, Ferlay J, Ward E, Forman D. Global cancer statistics. CA Cancer J Clin 2011;61:69-90.

5. Bolondi L, Sofia S, Siringo S, Gaiani S, Casali A, Zironi G, Piscaglia F, Gramantieri L, Zanetti M, Sherman M. Surveillance programme of cirrhotic patients for early diagnosis and treatment of hepatocellular carcinoma: a cost effectiveness analysis. Gut 2001;48:251-9.

6. A new prognostic system for hepatocellular carcinoma: a retrospective study of 435 patients: the cancer of the liver Italian program (clip) investigators. Hepatology 1998;28:751-5.

7. Siegel RL, Miller KD, Jemal A. Cancer statistics, 2016. CA Cancer J Clin 2016;66:7-30.

8. Cancer Incidence in Five Continents Volume VIII. Lyon: IARC; 2002.

9. Di Bisceglie AM. Hepatitis B and hepatocellular carcinoma. Hepatology 2009;49:S56-60.

10. Llovet JM, Di Bisceglie AM, Bruix J, Kramer BS, Lencioni R, Zhu AX, Sherman M, Schwartz M, Lotze M, Talwalkar J, Gores GJ; Panel of Experts in HCC-Design Clinical Trials. Design and endpoints of clinical trials in hepatocellular carcinoma. J Natl Cancer Inst 2008;100:698.

11. Mazzaferro V, Bhoori S, Sposito C, Bongini M, Langer M, Miceli R, Mariani L. Milan criteria in liver transplantation for hepatocellular carcinoma: an evidence-based analysis of 15 years of experience. Liver Transpl 2011;17 Suppl 2:S44-57.

12. Beasley RP. Hepatitis B virus. The major etiology of hepatocellular carcinoma. Cancer 1988;61:1942-56.

13. Shiina S, Hata Y, Niwa Y, Komatsu Y, Tanaka T, Yoshiura K, Hamada E, Ohshima M, Mutoh H, Kurita M, Nakata R, Ota S, Shiratori Y, Terano A, Sugimoto T, Taniguchi M, Uta Y, Tsukahara H, Tagawa K, Unuma T, Kawabe T, Okano K. Multiple-needle insertion method in percutaneous ethanol injection therapy for liver neoplasms. Gastroenterol Jpn 1991;26:47-50.

14. Lopez PM, Villanueva A, Llovet JM. Systematic review: evidence-based management of hepatocellular carcinoma - an updated analysis of randomized controlled trials. Aliment Pharmacol Ther 2006;23:1535-47.

15. Lencioni R. Loco-regional treatment of hepatocellular carcinoma. Hepatology 2010;52:762-73.

16. Livraghi T, Bolondi L, Lazzaroni S, Marin G, Morabito A, Rapaccini GL, Salmi A, Torzilli G. Percutaneous ethanol injection in the treatment of hepatocellular carcinoma in cirrhosis. A study on 207 patients. Cancer 1992;15:925-9.

17. Kuang M, Lu MD, Xie XY, Xu HX, Xu ZF, Liu GJ, Yin XY, Huang JF, Lencioni R. Ethanol ablation of hepatocellular carcinoma up to $5.0 \mathrm{~cm}$ by using a multipronged injection needle with high-dose strategy. Radiology 2009;253:552-61.

18. Lencioni R, Bartolozzi C, Caramella D, Paolicchi A, Carrai M, Maltinti G, Capria A, Tafi A, Conte PF, Bevilacqua G. Treatment of small hepatocellular carcinoma with percutaneous ethanol injection. Analysis of prognostic factors in 105 Western patients. Cancer 1995;76:1737-46.

19. Livraghi T, Giorgio A, Marin G, Salmi A, De Sio I, Bolondi L, Pompili M, Brunello F, Lazzaroni S, Torzilli G. Hepatocellular carcinoma and cirrhosis in 746 patients: long-term results of percutaneous ethanol injection. Radiology 1995;197:101-8.

20. Khan KN, Yatsuhashi H, Yamasaki K, Yamasaki M, Inoue O, Koga M, Yano M. Prospective analysis of risk factors for early intrahepatic recurrence of hepatocellular carcinoma following ethanol injection. J Hepatol 2000;32:269-278.

21. Livraghi T, Benedini V, Lazzaroni S, Meloni F, Torzilli G, Vettori C. Long term results of single session PEI in patients with large hepatocellular carcinoma. Cancer 1998;83:48-57.

22. Ebara M1, Okabe S, Kita K, Sugiura N, Fukuda H, Yoshikawa M, Kondo F, Saisho H. Percutaneous ethanol injection for small hepatocellular carcinoma: therapeutic efficacy based on 20-year observation. J Hepatol 2005;43:458-64.

23. McGahan JP, Brock JM, Tesluk H, Gu WZ, Schneider P, Browning PD. Hepatic ablation with use of radio-frequency electrocautery in the animal model. J Vasc Interv Radiol 1992;3:291.

24. Curley SA. Radiofrequency ablation of malignant liver tumors. Oncologist 2001;6:14-23.

25. Yin XY, Xie XY, Lu MD, Xu HX, Xu ZF, Kuang M, Liu GJ, Liang JY, Lau WY. Percutaneous thermal ablation of medium and large hepatocellular carcinoma: long-term outcome and prognostic factors. Cancer 2009;115:1914-23.

26. Rossi S, Buscarini E, Garbagnati F, Di Stasi M, Quaretti P, Rago M, Zangrandi A, Andreola S, Silverman D, Buscarini L. Percutaneous treatment of small hepatic tumors by an expandable RF needle electrode. AJR Am J Roentgenol 1998;170:1015-22.

27. Livraghi T, Goldberg SN, Lazzaroni S, Meloni F, Ierace T, Solbiati L, Gazelle GS. Hepatocellular carcinoma: radio-frequency ablation of medium and large lesions. Radiology 2000; 214:761-8. 
28. Curley SA, Izzo F, Ellis LM, Nicolas Vauthey J, Vallone P. Radiofrequency ablation of hepatocellular cancer in 110 patients with cirrhosis. Ann Surg 2000;232:381-91.

29. Iannitti DA, Dupuy DE, Mayo-Smith WW, Murphy B. Hepatic radiofrequency ablation. Arch Surg 2002;137:422-6.

30. Shiina S, Teratani T, Obi S, Hamamura K, Koike Y, Omata M. Nonsurgical treatment of hepatocellular carcinoma: from percutaneous ethanol injection therapy and percutaneous microwave coagulation therapy to radiofrequency ablation. Oncology 2002;62 Suppl 1:64-8.

31. Buscarini L, Buscarini E, Di Stasi M, Vallisa D, Quaretti P, Rocca A. Percutaneous radiofrequency ablation of small hepatocellular carcinoma: long-term results. Eur Radiol 2001;11:914-21.

32. Lencioni R, Cioni D, Crocetti L, Franchini C, Pina CD, Lera J, Bartolozzi C. Early-stage hepatocellular carcinoma in patients with cirrhosis: long-term results of percutaneous image-guided radiofrequency ablation. Radiology 2005;234:961-7.

33. Takahashi S, Kudo M, Chung H, Inoue T, Ishikawa E, Kitai S, Tatsumi C, Ueda T, Minami Y, Ueshima K, Haji S. Initial treatment response is essential to improve survival in patients with hepatocellular carcinoma who underwent curative radiofrequency ablation therapy. Oncology 2007;72 Suppl 1:98-103.

34. Choi D, Lim HK, Rhim H, Kim YS, Lee WJ, Paik SW, Koh KC, Lee JH, Choi MS, Yoo BC. Percutaneous radiofrequency ablation for early-stage hepatocellular carcinoma as a first-line treatment: long-term results and prognostic factors in a large singleinstitution series. Eur Radiol 2007; 17:684-92.

35. Tateishi R, Shiina S, Teratani T, et al. Percutaneous radiofrequency ablation for hepatocellular carcinoma. An analysis of 1000 cases. Cancer 2005;103:1201-9.

36. Lin SM, Lin CJ, Lin CC, Hsu CW, Chen YC. Randomised controlled trial comparing percutaneous radiofrequency thermal ablation, percutaneous ethanol injection, and percutaneous acetic acid injection to treat hepatocellular carcinoma of $3 \mathrm{~cm}$ or less. Gut 2005;54:1151-6.

37. Shiina S, Teratani T, Obi S, Sato S, Tateishi R, Fujishima T, Ishikawa T, Koike Y, Yoshida H, Kawabe T, Omata M. A randomized controlled trial of radiofrequency ablation versus ethanol injection for small hepatocellular carcinoma. Gastroenterology 2005;129:122-30.

38. Lin SM, Lin CJ, Lin CC, Hsu CW, Chen YC. Radiofrequency ablation improves prognosis compared with ethanol injection for hepatocellular carcinoma $<$ or $=4 \mathrm{~cm}$. Gastroenterology 2004;127:1714-23.

39. Lencioni R, Allgaier HP, Cioni D, Olschewski M, Deibert P, Crocetti L, Frings H, Laubenberger J, Zuber I, Blum HE, Bartolozzi C. Small hepatocellular carcinoma in cirrhosis: randomized comparison of radio-frequency thermal ablation versus percutaneous ethanol injection. Radiology 2003;228:235-40.

40. Brunello F, Veltri A, Carucci P, Pagano E, Ciccone G, Moretto P, Sacchetto P, Gandini G, Rizzetto M. Radiofrequency ablation versus ethanol injection for early hepatocellular carcinoma: a randomized controlled trial. Scand J Gastroenterol 2008;43:727-35.

41. Choi D, Lim HK, Kim MJ, Lee SH, Kim SH, Lee WJ, Lim JH, Joh JW, Kim YI. Recurrent hepatocellular carcinoma: percutaneous radiofrequency ablation after hepatectomy. Radiology 2004; 230:135-41.

42. Head HW, Dodd GD 3rd, Dalrymple NC, Prasad SR, El-Merhi FM, Freckleton MW, Hubbard LG. Percutaneous radiofrequency ablation of hepatic tumors against the diaphragm: frequency of diaphragmatic injury. Radiology 2007; 243:877-84.

43. Llovet JM, Vilana R, Brú C, Bianchi L, Salmeron JM, Boix L, Ganau S, Sala M, Pagès M, Ayuso C, Solé M, Rodés J, Bruix J; Barcelona Clínic Liver Cancer (BCLC) Group. Increased risk of tumor seeding after percutaneous radiofrequency ablation for single hepatocellular carcinoma. Hepatology 2001;33:1124-9.

44. de Baère T, Risse O, Kuoch V, Dromain C, Sengel C, Smayra T, Gamal El Din M, Letoublon C, Elias D. Adverse events during radiofrequency treatment of 582 hepatic tumors. AJR Am J Roentgenol 2003;181:695-700.

45. Kasugai H, Osaki Y, Oka H, Kudo M, Seki T; Osaka Liver Cancer Study Group. Severe complications of radiofrequency ablation therapy for hepatocellular carcinoma: an analysis of 3,891 ablations in 2,614 patients. Oncology 2007;72 Suppl 1:72-5.

46. Takaki H, Yamakado K, Nakatsuka A, Yamada T, Shiraki K, Takei Y, Takeda K. Frequency of and risk factors for complications after liver radiofrequency ablation under CT fluoroscopic guidance in 1500 sessions: single-center experience. AJR Am J Roentgenol 2013;200:658-64.

47. Facciorusso A, Serviddio G, Muscatiello N. Local ablative treatments for hepatocellular carcinoma: An updated review. World J Gastrointest Pharmacol Ther 2016;7:477-89.

48. Pacella CM, Bizzarri G, Magnolfi F, Cecconi P, Caspani B, Anelli V, Bianchini A, Valle D, Pacella S, Manenti G, Rossi Z. Laser thermal ablation in the treatment of small hepatocellular carcinoma: results in 74 patients. Radiology 2001;221:712-20.

49. Pacella CM, Francica G, Di Lascio FM, Arienti V, Antico E, Caspani B, Magnolfi F, Megna AS, Pretolani S, Regine R, Sponza M, Stasi R. Long-term outcome of cirrhotic patients with early hepatocellular carcinoma treated with ultrasound-guided percutaneous laser ablation: a retrospective analysis. J Clin Oncol 2009; 27:2615-21.

50. Pacella CM, Bizzarri G, Francica G, Bianchini A, De Nuntis S, Pacella S, Crescenzi A, Taccogna S, Forlini G, Rossi Z, Osborn J, Stasi R. Percutaneous laser ablation in the treatment of hepatocellular carcinoma with small tumors: analysis of factors affecting the achievement of tumor necrosis. J Vasc Interv Radiol 2005; 16:1447-57.

51. Arienti V, Pretolani S, Pacella CM, Magnolfi F, Caspani B, Francica G, Megna AS, Regine R, Sponza M, Antico E, Di Lascio FM. Complications of laser ablation for hepatocellular carcinoma: a multicenter study. Radiology 2008;246:947-55.

52. Majumdar A, Roccarina D, Thorburn D, Davidson BR, Tsochatzis E, Gurusamy KS. Management of people with early- or very earlystage hepatocellular carcinoma: an attempted network meta-analysis. Cochrane Database Syst Rev 2017;3:CD011650.

53. Liang P, Dong B, Yu X, Yu D, Wang Y, Feng L, Xiao Q. Prognostic factors for survival in patients with hepatocellular carcinoma after percutaneous microwave ablation. Radiology 2005;235:299-307.

54. Lu MD, Xu HX, Xie XY, Yin XY, Chen JW, Kuang M, Xu ZF, Liu GJ, Zheng YL. Percutaneous microwave and radiofrequency 
ablation for hepatocellular carcinoma: a retrospective comparative study. J Gastroenterol 2005;40:1054-60.

55. Dong B, Liang P, Yu X, Su L, Yu D, Cheng Z, Zhang J. Percutaneous sonographically guided microwave coagulation therapy for hepatocellular carcinoma: results in 234 patients. AJR Am J Roentgenol 2003;180:1547-55.

56. Yamashiki N, Kato T, Bejarano PA, Berho M, Montalvo B, Shebert RT, Goodman ZD, Seki T, Schiff ER, Tzakis AG. Histopathological changes after microwave coagulation therapy for patients with hepatocellular carcinoma: review of 15 explanted livers. Am J Gastroenterol 2003;98:2052-9.

57. Martin RC, Scoggins CR, McMasters KM. Safety and efficacy of microwave ablation of hepatic tumors: a prospective review of a 5-year experience. Ann Surg Oncol 2010;17:171-8.

58. Ma S, Ding M, Li J, Wang T, Qi X, Shi Y, Ming Y, Chi J, Wang Z, Tang X, Cui D, Zhang Y, Zhai B. Ultrasound-guided percutaneous microwave ablation for hepatocellular carcinoma: clinical outcomes and prognostic factors. J Cancer Res Clin Oncol 2017;143:131.

59. Choti MA. Surgical management of hepatocellular carcinoma: resection and ablation. J Vasc Interv Radiol 2002;13:S197-S203.

60. Huang J, Yan L, Cheng Z, Wu H, Du L, Wang J, Xu Y, Zeng Y. A randomized trial comparing radiofrequency ablation and surgical resection for HCC conforming to the Milan criteria. Ann Surg 2010;252:903-12.

61. Pompili M, Rapaccini GL, Covino M, Pignataro G, Caturelli E, Siena DA, Villani MR, Cedrone A, Gasbarrini G. Prognostic factors for survival in patients with compensated cirrhosis and small hepatocellular carcinoma after percutaneous ethanol injection therapy. Cancer 2001;92:126-35.

62. Giorgio A, Di Sarno A, De Stefano G, Scognamiglio U, Farella N, Mariniello A, Esposito V, Coppola C, Giorgio V. Percutaneous radiofrequency ablation of hepatocellular carcinoma compared to percutaneous ethanol injection in treatment of cirrhotic patients: an Italian randomized controlled trial. Anticancer Res 2011;31:2291-5. 